\title{
Scanning electron microscopy and $x$-ray microanalysis of mineral deposits in lungs of a patient with pleural mesothelioma
}

\author{
E M OPHUS,* G MOWÉ, K K OSEN, AND B GYLSETH
}

From the Institute of Occupational Health, Oslo, and the Department of Pathology, Rikshospitalet, Oslo, Noruay

ABSTRACT Scanning electron microscopy of lung tissue, ashed at low temperature, and obtained from an insulation worker who had died of pleural mesothelioma, showed the presence of numerous inorganic particles and fibres. A regional variation in fibre concentration in different tissue samples was found, and the size distribution of naked fibres and asbestos bodies was determined. By energy dispersive $x$-ray microanalysis the fibres were identified mainly as amphibole asbestos. This method also showed the presence of particles containing titanium and of fragments of diatom shells. Despite a mean concentration of $33 \times 10^{6}$ fibres per gram of dry tissue no significant lung fibrosis was found.

The causal relation between asbestos exposure and pleural and peritoneal mesothelioma was established in $1960.1^{1}$ Since then the increased incidence of mesothelioma in individuals exposed to asbestos has been widely documented. ${ }^{2}$ The relation to asbestos exposure may, however, be obscured by a long period between initial exposure and the appearance of the tumour. The dose required for the initiation of a mesothelioma is small, and may be acquired by non-occupational exposure to asbestos. ${ }^{3}$

$A$ relation between the lung asbestos burden and asbestos-related diseases has been suggested. ${ }^{4-6}$ Identification and quantification of mineral particles in the lungs requires the use of microanalytical techniques. ${ }^{7}$ For in situ identification of inorganic substances in lung tissue-for instance, in the study of pneumoconiosis-scanning electron microscopy coupled with energy dispersive $x$-ray microanalysis has proved particularly useful. ${ }^{8}$ This instrumentation has also been used for quantitative analysis of mineral fibres in lung residues obtained by tissue degradation methods. Gylseth et al ${ }^{9}$ reported that low temperature plasma ashing is the most convenient and reliable technique for this purpose.

In the present study we have used these methods

\footnotetext{
* Present address: University of Trondheim, Norwegian Institute of Technology, Division of Industrial Management, N 7034 Trondheim-NTH, Norway.
}

Received 2 July 1979

Accepted 5 September 1979 to identify and quantify inorganic particles and fibres in different parts of lung tissue taken from an insulation worker who died of pleural mesothelioma.

\section{Case history}

OCCUPATIONAL EXPOSURE

The patient was born in 1920. A complete occupational history was obtained in 1976, when he participated in an epidemiological investigation. From 1935 to 1952 he was engaged in insulation work in industry and shipyards. During this period (17 years), he was exposed to various insulation materials such as asbestos (mainly amphibole minerals), man-made mineral fibres, cork, and diatomaceous earth. No occupational exposure to asbestos was recorded after 1952. The lapsed time from first exposure until death in 1978 was 43 years. He started smoking when 15 years old and smoked 10-15 cigarettes a day.

\section{SYMPTOMS AND SIGNS}

In 1976 he developed slight dyspnoea during physical activity. The lung function was normal: FVC $5000 \mathrm{ml}$ and FEV $_{1} 3800 \mathrm{ml}$. Radiographic examination showed a slight pleural reaction on the right side but no evidence of parenchymal changes (fig 1(a)). During summer 1977 he developed progressive dyspnoea. In August 1977 a large pleural effusion was seen on the right side (fig 1(b)). Cytological examination of fluid from the right pleura 

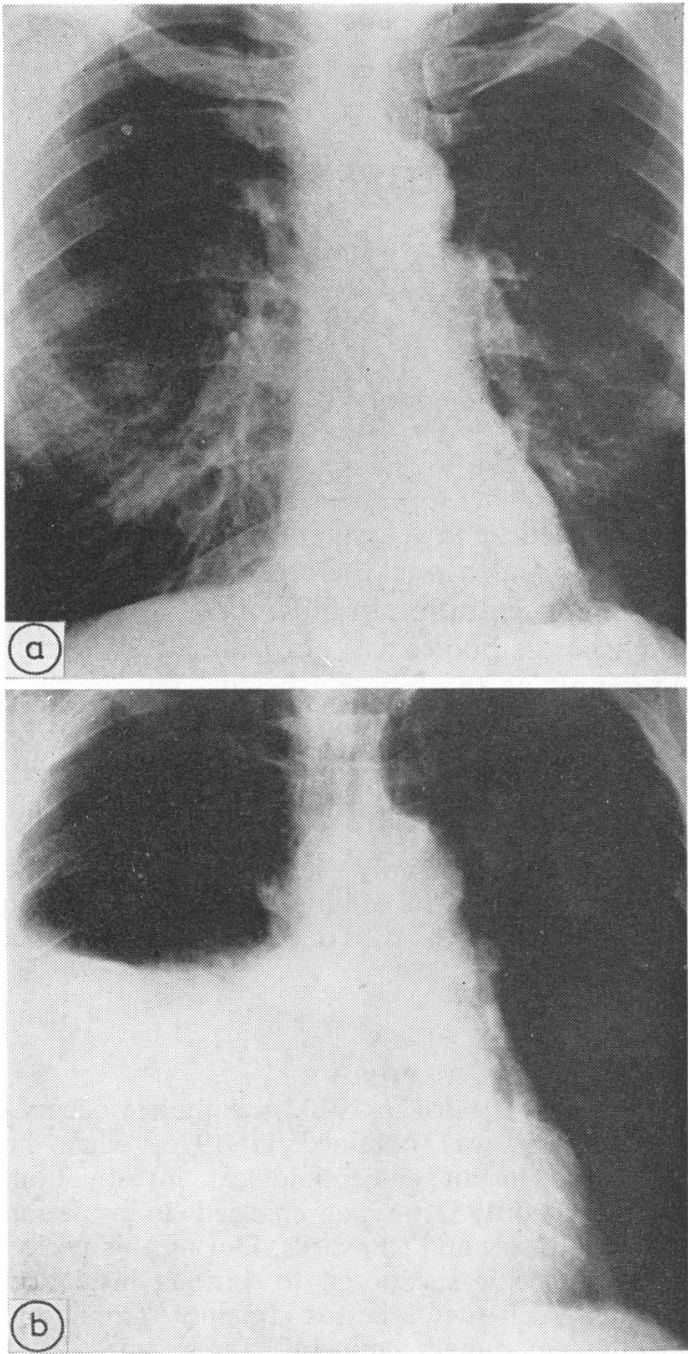

Fig 1 Chest films taken (a) two years before death; (b) 17 months later (six months before death). showed malignant, probably epithelial, cells. He became progressively ill until death in March 1978.

\section{Methods \\ NECROPSY}

A routine post-mortem examination of the viscera and the brain was performed. Tissue samples, including large slices of the lungs, were fixed by immersion in buffered $10 \%$ formalin. Samples for histological examination were embedded in paraffin. Besides the routine haematoxylin-azophloxinesaffron procedure, the lung sections were stained by periodic acid-Schiff (PAS) and a modification of Mallory's method for connective tissue. Tumour sections were stained by several methods: (1) PAS with and without preincubation for one hour at $37^{\circ} \mathrm{C}$ in $0.5 \%$ malt diastase; (2) alcian blue with and without preincubation for 18 hours at $37^{\circ} \mathrm{C}$ in a solution of $1.25 \mathrm{mg}$ testicular hyaluronidase in $50 \mathrm{ml}$ $0.2 \mathrm{M}$ acetate buffer, $\mathrm{pH} 5 \cdot 6^{10}$; and (3) Hale's colloidal iron ${ }^{11}$ with and without hyaluronidase digestion, as described above. After removal of the paraffin wax small pieces of tumour tissue were hydrated, osmicated, dehydrated, and embedded in Epon. Semithin sections were stained with $0.1 \%$

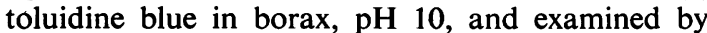
light microscopy. Ultrathin sections were stained with uranyl acetate and lead citrate and examined in the transmission electron microscope.

\section{SCANNING ELECTRON MICROSCOPY}

The concentration of fibres in the lungs was determined by a scanning electron microscope (SEM) according to the method described by Gylseth et al. ${ }^{9}$ Two lungslices (about $3 \times 1 \times 1 \mathrm{~cm}$ ), including pleural and parenchymal tissues, were divided into three pieces each by cuts parallel to the pleura. After drying and low temperature plasma ashing followed by slight acid treatment, the ash residue was dispersed in water and collected on Nuclepore filters. The fibre

Fig 2 (a)-(f) are from a tumour metastasis in thigh muscles; (g) is from the lung; (e) is an electron micrograph; others are light micrographs. (a) Tumour shows cell-lined slits and irregular groups of polygonal cells in an abundant connective tissue stroma that also contains remnants of muscle fibres (arrowheads) and moderate amounts of leucocytes. (Paraffin section, haematoxylin-azophloxine-saffron, $\times 85$.) (b) Cell from lumen of a slit with a large, metachromatic vacuole $(v)$. (c) Tumour cells with irregular nuclei $(n)$ and numerous apical microvilli (arrowheads). ((b) and (c) Epon sections, toluidine blue, $\times 1200$.) (d) Tumour cells with apical microvilli (arrowheads) are seen lining a slit. Two vacuolated cells are embedded in underlying stroma. Vacuole (v1) of upper cell has a smooth wall and is filled with a PAS-negative substance. Lower vacuole (v2) appears empty with a ragged wall possibly provided with microvilli. (Paraffin section, PAS with diastase, $\times 1200$.) (e) Electron micrograph from apical end of a tumour cell with long and slender microvilli (arrowheads), (n) part of nucleus. ( $\times 25$ 000.) (f) Tumour cell vacuole $(v)$ with a positively stained content. Note also positively reacting coarse granules (arrows) between cells. (Paraffin section, Hale's colloidal iron without hyaluronidase, $\times$ 1200.) (g) Alveolar wall with numerous capillaries (c). (Paraffin section, PAS, $\times 1200$.) 

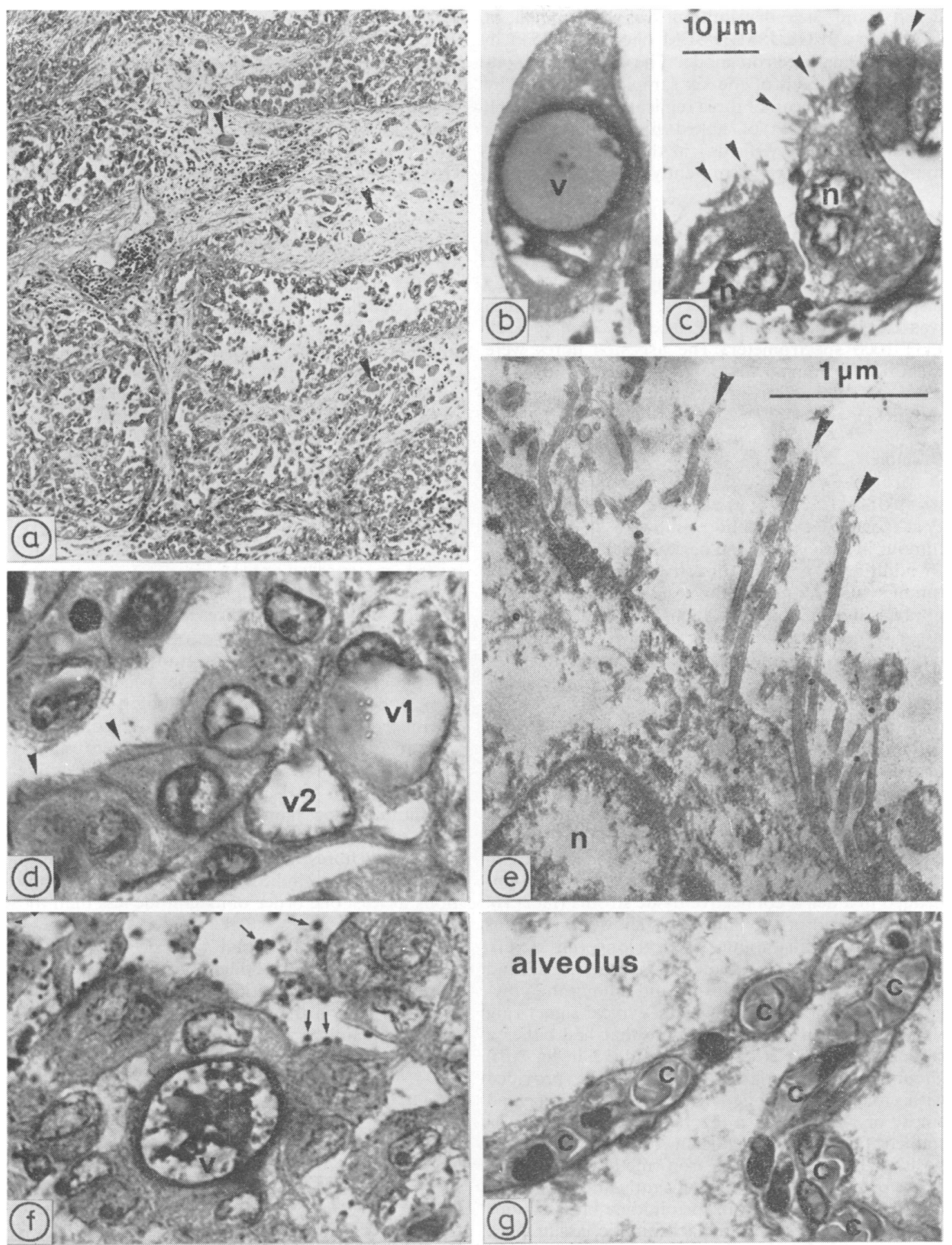
density and size distribution was determined at $4500 \times$ in a JEOL JSM 35 SEM, operated at $25 \mathrm{kv}$ in the secondary electron mode. The mean fibre concentration in each of the six samples was given by the arithmetic mean of three replicate counts. In each count the number of naked fibres and asbestos bodies in 200 "view fields" in the SEM was determined by scanning intermittently across the filter.

\section{$x$-RAY MICROANALYSIS}

The elemental composition of mineral particles and fibres, including naked fibres and asbestos bodies, was determined in the SEM by means of energy dispersive $x$-ray microanalysis. The investigation was carried out using a Princeton Gamma Tech PGT-1000 spectrometer. The asbestos fibres were identified by comparing the $x$-ray spectra with those obtained by analysis of standard UICC asbestos samples.

\section{Results}

PATHOLOGICAL ANATOMICAL EXAMINATION Post-mortem examination showed a malignant tumour in the visceral and parietal pleura bilaterally. In addition a massive, directly invasive growth of tumour was found in the mediastinum, the diaphragm, the abdominal wall, and the retroperitoneal tissue. These structures were all considerably enlarged and appeared like a continuous mass of tumour weighing about $5 \mathrm{~kg}$. Distant metastases were found in the muscles of the thigh bilaterally, the myocardium, the intestinal submucosa, the vertebral column, the liver, and the kidneys. The metastases, like the primary tumour, thus seemed to grow preferentially in mesenchymal tissues.

On microscopy the tumour was found to have a pure epithelial character being composed in part of cuboidal or cylindrical cells lining slit-like cavities, in part by more undifferentiated polygonal cells embedded in a dense connective tissue stroma (fig 2(a)). The apical end of the lining cells showed numerous slender microvilli, about 3-4 $\mu \mathrm{m}$ long (fig 2(c-e)). Round cells with a vacuolated cytoplasm were found both in the lumina of the slits and among the polygonal cells. Some of them had a typical signet ring shape with a large single vacuole that had either a smooth (v1 in fig $2(\mathrm{~d})$ ) or a ragged (v2 in fig 2(d)) circumference, the latter possibly being provided with microvilli. While most vacuoles appeared empty or washed out, a few had a content that was stained faintly by the alcian blue and distinctly positive by the colloidal iron method (fig 2(f)). These reactions were not significantly affected by the hyaluronidase incubation. In toluidine blue sections the filled vacuoles were metachromatic, assuming a purple colour (fig 2(b)). All viable tumour cells were PAS-negative, but among them were found positively stained cellular debris and scattered coarse granules, which were stained positively also by the colloidal iron method (fig 2(f), arrows). The PAS and colloidal iron staining of the granules disappeared after digestion with diastase and hyaluronidase, respectively. The tumour cells showed only scattered mitoses and a moderate nuclear pleomorphy.

In the lungs the alveolar tissue was invaded by tumour cells only in the immediate vicinity of the tumour-containing pleura. There was no significant fibrosis or emphysema of the lungs as judged by the gross examination and the microscopy of routine, PAS, or Mallory stained sections. The bronchioli, alveolar ducts, and alveolar sacs seemed normal in size and, as illustrated in fig $2(\mathrm{~g})$, the alveolar walls appeared delicate with no discernible changes in the density of capillaries or collagen fibres. The peribronchial connective tissue nevertheless contained considerable amounts of anthracotic pigments, birefractive crystals, and asbestos bodies, also present in the enlarged, tumour-invaded mediastinal lymph nodes.

\section{FIBRE CONCENTRATION}

Table 1 shows the fibre concentration in successive regions of the two lung slices. The mean concentration was $33 \times 10^{6}$ fibres/g of dry tissue with a significantly larger concentration in the central sample of slice 2 . Ninety-two per cent of the fibres gave a positive asbestos (amphibole) identification by the $x$-ray microanalysis. The true proportion of asbestos fibres may have been higher because fibres less than $0 \cdot 1 \mu \mathrm{m}$ in diameter could not be identified, due to the low signal-to-background ratio. Chrysotile was not detected. Non-asbestos fibres were identified by $x$-ray microanalysis as other fibre-forming silicates. Few fibres were found in the thickened and calcified pleura, indicating pleural fibre concentrations at least one order of magnitude less than those of the lung tissue.

About $7 \%$ of the total number of fibres were classified as asbestos bodies (fig 3(a)). The central fibre could not be identified, due to the $x$-ray signal from the iron in the coating, in $17 \%$ of the bodies. In the remaining $83 \%$ the coating was fragmented

Table 1 Regional distribution of fibre concentrations in the two lung slices

\begin{tabular}{lll}
\hline $\begin{array}{l}\text { Distance from } \\
\text { pleura }(\mathrm{cm})\end{array}$ & \multicolumn{2}{l}{ No of fibres/g dry lung $\times 10^{8}$ (range) } \\
\cline { 2 - 3 } & Slice 1 & Slice 2 \\
\hline $0-1$ & $22(20-23)$ & $24(22-25)$ \\
$1-2$ & $29(27-31)$ & $24(23-26)$ \\
$2-3$ & $32(29-33)$ & $66(55-82)$ \\
\hline
\end{tabular}



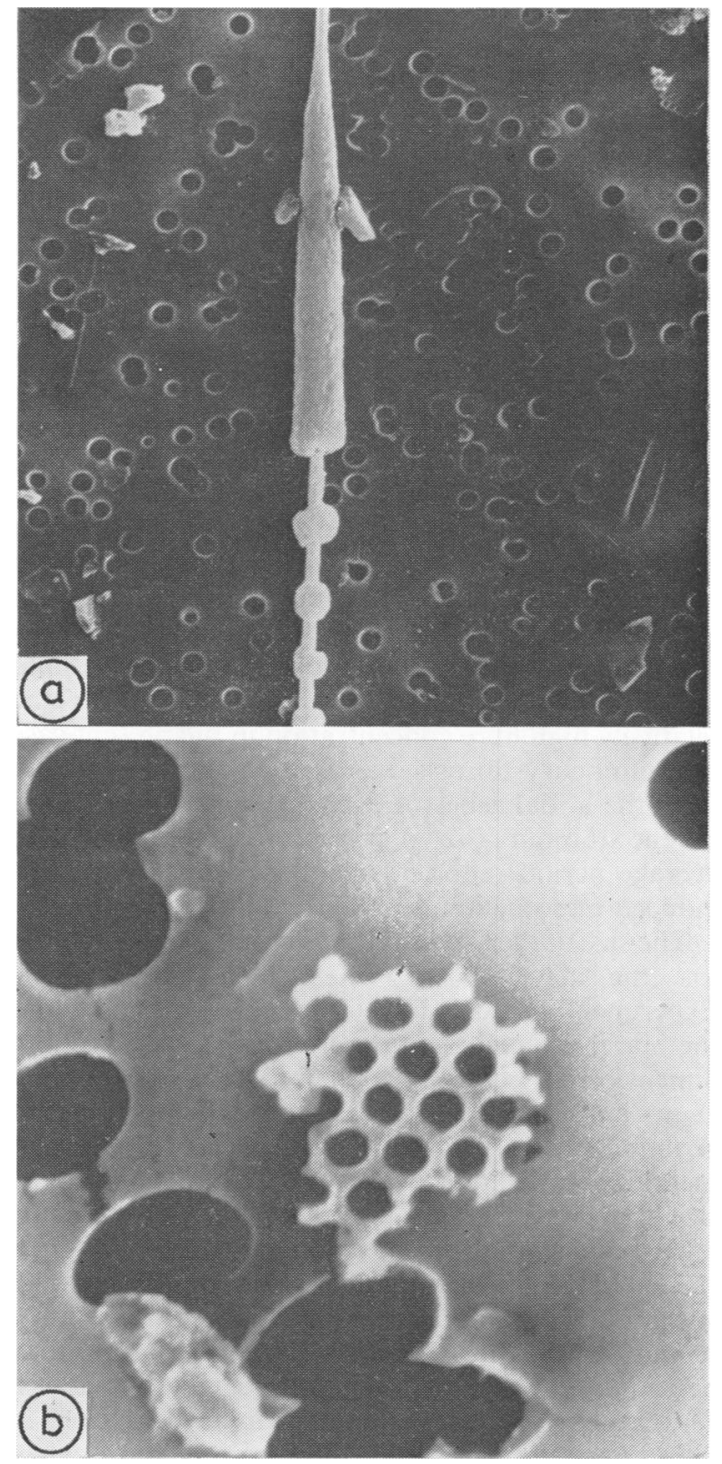

Fig 3 Lung tissue incinerated and collected on a Nuclepore filter. (a) Asbestos body $(\times 2600)$. (b) Diatom fragment $(\times 15000)$.

Table 2 Regional distribution of asbestos bodies in the two lung slices. Concentrations are expressed in percentage of total number of fibres within each sample

\begin{tabular}{lll}
\hline $\begin{array}{l}\text { Distance from } \\
\text { pleura }(\mathrm{cm})\end{array}$ & \multicolumn{2}{l}{ Pcrcentage asbestos bodies } \\
\cline { 2 - 3 } & Slice 1 & Slice 2 \\
\hline $0-1$ & $7 \cdot 6$ & $9 \cdot 6$ \\
$1-2$ & $11 \cdot 5$ & $6 \cdot 5$ \\
$2-3$ & $6 \cdot 3$ & $2 \cdot 8$ \\
\hline
\end{tabular}

and showed the central core for identification. Only amphibole minerals (mainly crocidolite) were found. Table 2 gives the relative proportion of asbestos bodies in different parts of the tissue. There were no systematic differences related to the distance of the sample from the pleural surface.

\section{FIBRE SIZE DISTRIBUTION}

While the fibre concentrations were higher in the deeper than in peripheral parts of the lung (table 1), the length distribution was relatively constant, although fibre lengths ranged from 1 to $50 \mu \mathrm{m}$. In all samples nearly $70 \%$ of the naked fibres were less than $5 \mu \mathrm{m}$ in length. The diameters of the fibres never exceeded $2 \mu \mathrm{m}$, and $95 \%$ of the fibres were less than $1 \mu \mathrm{m}$ in diameter.

The length distribution of the central fibres in the asbestos bodies differed from that of the naked fibres (fig 4(a)). About $90 \%$ of the central fibres exceeded $5 \mu \mathrm{m}$ in length compared with $30 \%$ for the naked ones. The diameter distribution of the coated fibres showed only a small bias towards increased values as compared with the naked ones (fig 4(b)). About $2.0 \times 10^{6}$ naked fibres and $1.5 \times 10^{6}$ coated fibres longer than $10 \mu \mathrm{m}$ were present per gram of dry lung tissue.

\section{OTHER PARTICLES}

Fragments of diatom shells (kieselguhr) that were often found in the lung tissue were identified by morphology (fig 3(b)) and the pure silicon $\mathrm{K} \alpha x$-ray spectrum. Cases of diatomaceous earth pneumoconiosis have been described. ${ }^{12}$ On average, $1.4 \times$ $10^{6}$ shell fragments were found per gram of dry lung tissue. The distribution of diatom shells resembled
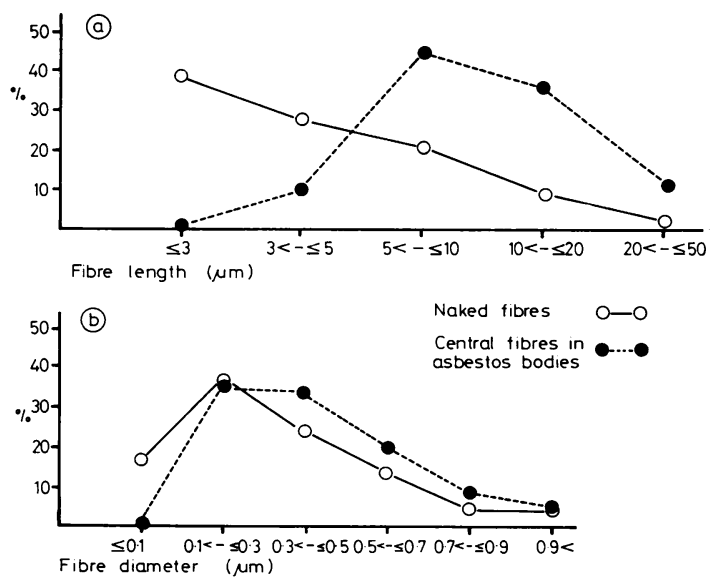

Fig 4 Size distributions of 1459 naked fibres and 114 central fibres in asbestos bodies. (a) Length. (b) Diameter. 
that of asbestos bodies and showed no preferential site for deposition in the lung.

Further investigation of the low temperature ashed pleural and parenchymal tissues showed various particles containing silicon or titanium. The latter presumably consisted of titanium dioxide pigments, which may behave as a mild irritant in the pulmonary interstitium. ${ }^{13} 14$

\section{Discussion}

According to the necropsy findings the patient died from a malignant mesothelioma present in both pleurae, but possibly originating on the right side and spreading to several other locations either by direct invasion or metastasis. The thickened, tumourinvaded pleurae evidently must have affected both the respiratory space and the respiratory movements, but in agreement with the radiographic findings two years before death we found no discernible fibrosis or emphysema of the lungs.

Despite the epithelial character of the tumour, the existence of a metastatic carcinoma or a bronchioloalveolar cell carcinoma could be ruled out by the electron microscopical appearance of the tumour cells, particularly their long and slender microvilli. According to Wang ${ }^{15}$ these microvilli constitute a highly characteristic feature of malignant mesotheliomas. Similar microvilli are found only in the adenomatoid tumours of the genital tracts, which are also supposed to be of a mesothelial origin. ${ }^{16}$ Microvilli of carcinomas, including pulmonary tumours, are, as a rule, shorter, broader, and more irregularly club-shaped. ${ }^{17}$ In the present case the absence of any other possible primary tumour also strongly favoured the diagnosis of a mesothelioma.

Although these findings leave no doubt that the present tumour was a pure epithelial mesothelioma, we have not been able to prove the presence of hyaluronic acid, which is a characteristic feature of such tumours. ${ }^{10}$ Tumour cell vacuoles with villous or smooth walls containing alcian blue material labile to hyaluronidase have been described by Wang ${ }^{15}$ in two cases of diffuse mesotheliomas. In our material the cell vacuoles appeared very much like those illustrated by Wang, ${ }^{15}$ except that most of them seemed empty or washed out. A few vacuoles may have contained acid mucopolysaccharides as judged by their metachromasia, positive staining by alcian blue and colloidal iron, and negative PAS-staining. ${ }^{18}$ In our hands, however, these staining reactions were not significantly changed by preincubation with hyaluronidase. The discrepancy may possibly be described to a prolonged formalin fixation that may have removed the water-soluble hyaluronic acid, leaving only remnants of a less soluble and more hyaluronidase-stable substance.

With respect to the composition of the PAS- and colloidal iron-positive granules found between the tumour cells, their loss of PAS-staining after diastase digestion speaks in favour of glycogen. It is doubtful, however, whether this can explain their lability to hyaluronidase.

According to the occupational history and the burden of fibre in the lung, this man must have had considerable exposure to asbestos. The mean concentration of fibres, $33 \times 10^{6} / \mathrm{g}$ of dry lung tissue, is significantly higher than in people with low or unknown occupational exposure (Mowe et al at the Vth International Conference on Pneumoconiosis in Caracas, 29 October-3 November 1978). Similar fibre concentrations have been reported by Ashcroft and Heppleston ${ }^{4}$ in patients with mesothelioma with mild asbestosis. According to them a significant correlation exists between the lung fibre concentration and the degree of pulmonary fibrosis, in mild and moderate grades of asbestosis. Despite the relatively high fibre concentration in the present case no pulmonary fibrosis was found. The lapsed time from the initial asbestos exposure to the appearance of the tumour (42 years) corresponds with the average period reported in other cases of asbestosinduced mesothelioma. ${ }^{2}$

The size of the asbestos fibres may be of importance for the development of mesothelial tumours. Experimental studies by Stanton et al ${ }^{19}$ showed that the carcinogenicity probably depended on fibre dimensions. According to them, fibres longer than $8 \mu \mathrm{m}$ and thinner than $1.5 \mu \mathrm{m}$ yield the highest probability of pleural sarcomas. In future studies of pleural mesotheliomas both the concentration and the size distribution of coated and naked fibres in the lung tissue should be determined.

This study indicates that there may be regional variations in the fibre concentration within the same segment of the lung. Possibly, greater variations may be found between different lung segments or lobes. The existence of intra- and inter-lobular variations in fibre concentration should be borne in mind when designing comparative studies of asbestos fibre levels in populations with various occupational exposures or with various asbestos-related diseases. ${ }^{6}$ For such investigations, whole slices of both lungs should be used for systematic sampling. Care should also be taken in comparing quantitative data from studies where different techniques of sample preparation or counting procedures have been applied. ${ }^{9}$

The evaluation of the lung asbestos burden is further complicated by the tendency of asbestos fibres, particularly chrysotile, to be cleared from the tissue in vivo. ${ }^{20}$ In our patient many amphibole asbestos fibres were found, in agreement with the 
occupational history. Yet the presence of chrysotile cannot be excluded, because fibres (fibrils) too thin to be identified by the $x$-ray microanalysis may represent chrysotile degraded in vivo or during sample preparation. The predominance of amphibole cores in asbestos bodies is in accordance with the findings of Churg and Warnock. ${ }^{21}$

The proportion of coated fibres $(7 \cdot 1 \%)$ in this patient has been found in other cases with a high exposure to asbestos (Mowé et al at the Caracas conference, 1978). Botham and Holt ${ }^{22}$ found that mature asbestos bodies have a beaded appearance that develops with time and finally leads to fragmentation of the body. Despite the fact that our patient had not been occupationally exposed to asbestos fibres during the last 20 years of life, nearly $17 \%$ of the asbestos bodies were covered with an unbroken iron/protein sheet, and $8 \%$ had only the bare ends protruding from the cover. This observation suggests the presence of newly formed, immature bodies in the lungs, and may indicate that asbestos fibres undergo coating and fragmentation several times.

The presence of several other minerals in the lungs is consistent with the occupational history of the patient, but the significance of these agents in the pathogenesis of the mesothelioma is uncertain.

\section{References}

${ }^{1}$ Wagner JC, Sleggs CA, Marchand P. Diffuse pleural mesothelioma and asbestos exposure in the North Western Cape Province. Br J Ind Med 1960;17:260-71.

${ }^{2}$ Selikoff IJ, Lee DHK. Asbestos and disease. New York: Academic Press, 1978:241-306.

${ }^{3}$ Newhouse ML, Thompson $\mathrm{H}$. Mesothelioma of pleura and peritoneum following exposure to asbestos in the London area. Br J Ind Med 1965;22:261-9.

4 Ashcroft T, Heppleston AG. The optical and electron microscopic determination of pulmonary asbestos fibre concentration and its relation to the human pathological reaction. J Clin Pathol 1973;26:224-34.

${ }^{5}$ Whitwell F, Scott J, Grimshaw M. Relationship between occupations and asbestos-fibre content of the lung in patients with pleural mesothelioma, lung cancer, and other diseases. Thorax 1977;32:377-86.

'Bignon J, Sebastien P, Fondimare A, et al. Étude quantitative et qualitative des fibres d'amiante dans l'appareil respiratoire humain. Paris: Institut de Recherche Universitaire sur l'Environnement, 1978.

' Rüttner JR, Spycher MA, Sticher H. The detection of etiologic agents in interstitial pulmonary fibrosis. Human Pathol 1973;4:497-512.

${ }^{8}$ Funahashi A, Siegesmund KA, Dragen RF, Pintar K. Energy dispersive $x$-ray analysis in the study of pneumoconiosis. Br J Ind Med 1977;34:95-101.

${ }^{9}$ Gylseth B, Ophus EM, Mowé G. Determination of inorganic fiber density in human lung tissue by scanning electron microscopy after low temperature ashing. Scand J Work, Environ Health 1979;5:151-7.

${ }^{10}$ Wagner JC, Munday DE, Harington JS. Histochemical demonstration of hyaluronic acid in pleural mesotheliomas. J Pathol Bacteriol 1962;84:73-8.

${ }^{11}$ Culling CFA. Handbook of histopathological techniques (including museum techniques). 2nd ed. London: Butterworth, 1963:233.

12 Dutra FR. Diatomaceous earth pneumoconiosis. Arch Environ Health 1965;11:613-9.

${ }^{13}$ Elo R, Määttä K, Uksila E, Arstila AU. Pulmonary deposits of titanium dioxide in man. Arch Pathol 1972; 94:417-24.

${ }^{14}$ Määttä K, Arstila AU. Pulmonary deposits of titanium dioxide in cytologic and lung biopsy specimens. Lab Invest $1975 ; 33: 342-6$.

15 Wang N-S. Electron microscopy in the diagnosis of pleural mesotheliomas. Cancer 1973;31:1046-54.

${ }^{16}$ Salazar H, Kanbour A, Burgess F. Ultrastructure and observations on the histogenesis of mesotheliomas "adenomatoid tumors" of the female genital tract. Cancer 1972;29:141-52.

${ }^{17}$ Kuhn C. Fine structure of bronchiolo-alveolar cell carcinoma. Cancer 1972;30:1107-18.

18 Pearse AGE. Histochemistry. Theoretical and applied. 3rd ed. Edinburgh and London: Churchill Livingstone, 1972:1030-2.

${ }^{19}$ Stanton MF, Layard M, Tegeris A, Miller E, May M, Kent E. Carcinogenicity of fibrous glass: pleural response in the rat in relation to fiber dimension. $J$ Nall Cancer Inst 1977;58:587-603.

${ }^{20}$ Le Bouffant $\mathrm{L}$. Investigation and analysis of asbestos fibers and accompanying minerals in biological materials. Environ Health Perspect 1974;9:149-53.

${ }^{21}$ Churg A, Warnock ML. Correlation of quantitative asbestos body counts and occupation in urban patients. Arch Pathol Lab Med 1977;101:629-34.

22 Botham SK, Holt PF. Development of asbestos bodies on amosite, chrysotile, and crocidolite fibres in guinea-pig lungs. $J$ Pathol $1971 ; 105: 159-67$. 